\title{
The Frequency of Sarcopenia and Associated Factors in Older Patients with Rheumatoid Arthritis
}

\author{
(1) İrfan Karahan1, (1) Sevgi Aras², (1) Murat Varlı², (1) Esat Çınar², (1) Özlem Karaarslan Cengiz², (1) Teslime Atlı³ \\ ${ }^{1}$ Ankara University Faculty of Medicine, Department of Internal Medicine, Ankara, Turkey \\ ${ }^{2}$ Ankara University Faculty of Medicine, Department of Internal Medicine, Division of Geriatrics, Ankara, Turkey \\ ${ }^{3}$ Ankara Güven Hospital, Clinic of Internal Medicine, Division of Geriatrics, Ankara, Turkey
}

\begin{abstract}
Objective: Rheumatoid arthritis (RA) is a progressive, systemic, and autoimmune disease. On the other hand, sarcopenia is a Geriatric syndrome characterized by a decrease in muscle mass and strength. Identifying and detecting factors associated with sarcopenia is critical for screening and treatment of older patients with RA.
\end{abstract}

Materials and Methods: First off, Muscle Mass index and Free Fat Mass index in 30 young, healthy males and 30 young, healthy females were assessed using a bioimpedance analyzer to find cut-off values for sarcopenia diagnosis. Then, 100 RA patients over 65 years were recruited for the same test, and patients with a value 2 standard deviation below the calculated cut-off levels were diagnosed as having low muscle mass. Patients who had low muscle mass plus (low handgrip strength or low gait speed) were diagnosed as sarcopenic. In addition, the sample was divided into two groups as sarcopenic and non-sarcopenic. Demographic characteristics, medication history, bioimpedance value, daily life activities, frailty rate, malnutrition rate, hemoglobin level, 25-OH vitamin D level, glomerular filtration rate, rheumatoid factor, anti-cyclic citrullinated peptide seropositivity, and erythrocyte sedimentation rates (ESR) and C-reactive protein (CRP) level were compared between the groups.

Results: The sarcopenic group was older than the other group. Nobody was found to use any biological agent in the sarcopenic group, but 8 nonsarcopenic patients had used biological agents previously. Malnutrition and frailty rate and level of dependence in activities of daily living were higher in the sarcopenic group than in the non-sarcopenic group. Not with standing, both groups had similar Disease Activity score-28; ESR and CRP level were higher in the sarcopenic group.

Conclusion: The prevalence of sarcopenia rises with aging, malnutrition, and frailty. Accompanying with an autoimmune disease like RA, sarcopenia causes disabilities, dependence, and mortality at higher rates. Overall, sarcopenia and its consequences should be considered for the geriatric population.

Keywords: Rheumatoid arthritis, sarcopenia, bioimpedance analysis

\section{Introduction}

Sarcopenia is a generalized and progressive skeletal muscle disorder that is associated with an increased likelihood of adverse outcomes, including falls, physical disability, and mortality. The disease is characterized by low muscle strength, low muscle quantity or quality, and low physical performance (1). The European Working Group on Sarcopenia in Older People (EWGSOP) held another meeting to update the definition of sarcopenia in early 2018 and emphasized the importance of muscle quality (2). Etiopathogenesis of sarcopenia includes age, endocrinological changes, nutritional status, comorbidities, defective immune response, chronic drug use, etc (3). On the other hand, rheumatoid arthritis (RA) is a chronic, progressive, and autoimmune disorder that leads to deformities, disabilities, impairment of physical acitivity and extraarticular involvements. RA is the most frequent one between inflammatory arthritis. Also, muscle-specific symptoms and signs are common in

Address for Correspondence: İrfan Karahan, Ankara University Faculty of Medicine, Department of Internal Medicine, Ankara, Turkey Phone: +90 5447396991 E-mail: irfan_karahan@yahoo.com ORCID: orcid.org/0000-0003-4669-1751

Received: Apr 28, 2020 Accepted: May 12, 2020

Cite this article as: Karahan I, Aras S, Varlı M, Çınar E, Karaarslan Cengiz Ö, Atlı T. The Frequency of Sarcopenia and Associated Factors in Older Patients with Rheumatoid Arthritis. Eur J Geriatr Gerontol 2020;2(2):41-45

๑Copyright 2020 by the Academic Geriatrics Society / European Journal of Geriatrics and Gerontology published by Galenos Publishing House. 
patients with RA (4). It is shown that sarcopenia is common in RA patients because of multidrug treatments and the effects of the disease itself (5).

Many changes occur in the metabolism and physiological reserve decrease by aging (6). Various studies show that sarcopenia affects physiological reserve adversely and worsen prognosis. The disease can also lead to disabilities and impair quality of life or dependence in activities of daily living (ADL) (7-9). Sarcopenia is a significant health problem and expected to be increasingly prevalent in the next decades (10). Therefore, identifying sarcopenia-associated factors in older RA patients may be a useful guide for the diagnosis and management of the disease. The present study aimed at investigating the prevalence of sarcopenia and associated factors in the geriatric population with RA.

\section{Materials and Methods}

The cross-sectional study included 100 RA patients over 65 years admitted to Ankara University, Geriatrics, and Rheumatology Outpatient Clinics between March 2014 and October 2014. All patients were diagnosed based on the ACR/EULAR 2010 criteria. Sarcopenia was diagnosed with EWGSOP 2010 criteria (1). According to this criteria; the diagnosis is based on documentation of low muscle mass plus (low muscle strength or low physical performance). We evaluated muscle strength with Handgrip test (low handgrip strength $<30 \mathrm{~kg}$ for males, $<20 \mathrm{~kg}$ for females) and physical performance with gait speed test (low speed $<0.8 \mathrm{~m} / \mathrm{sec}$ ). At the time of data collection, there were no widely acceptable standart validated values of TANITA results for Turkish people; for this reason, before the evaluation of RA patients, we analysed a healthy young Turkish control group with TANITA in order to find index values. 30 young, healthy females (median age: 33 ) and 30 young, healthy males (median age: 35 ) were recruited to be assessed with TANITA$\mathrm{BC} 420 \mathrm{MA}^{\circledR}$ to identify the cut-off value for determining the status of muscle mass. Fat-free mass (FFM), fat percentages, fatfree mass indices (FFMIs), and muscle mass indices (MMIs) were calculated, and the value 2 standard deviation below the cut-off level for the young was identified as the cut-off level for low muscle mass. FFMls were calculated as FFM/(height $x$ height), and MMls were calculated as muscle mass/(height $x$ height). Apart from such calculations, demographic characteristics of admitted RA patients were noted, and these patients were interrogated for diease duration, comorbidities, such as diabetes and hypertension, smoking, and alcohol use. Disease Activity score-28 DAS-28 was used to determine the severity of RA. Uses of glucocorticoids, nonsteroid anti-inflammatory drugs, conventional disease modified anti-rheumatic drugs (cDMARDs), biological DMARDs (bDMARDs), and statin were checked for the medication history. It was assessed if urinary incontinence was present. The comprehensive geriatric assessment was also examined. While the Katz index was used for ADL, the LawtonBrody index was used for instrumental activities of daily living (IADL). The Yesavage Geriatric Depression scale-short form was used to evaluate the depression status of the patients. While the frailty was assessed with the Fried Frailty index, the nutritional status was evaluated with the Mini Nutritional Assessment. The lengths of middle upper arm and calves were obtained from initial anthropometric measurements. Body mass indices were calculated as weight/(height $x$ height). A handgrip test by a hand dynamometer was used to assess muscle strength. Total body water, fat percentages, FFMIs, and MMls of all RA patients were calculated. Hemoglobin levels, estimated GFR (with modified diet renal disease formula), erythrocyte sedimentation rates (ESR), C-reactive protein (CRP) levels, and 25-0H vitamin $D$ levels were evaluated in laboratory analyses. Rheumatoid factor (RF) and anti-cyclic citrullinated peptide (anti-CCP) were examined for seropositivity.

\section{Statistics}

SPSS for Windows $15^{\circledR}$ was used for all statistical analyses. Accordingly, descriptive statistics were given as mean \pm standart deviation for normally distributed data, and as median (minimum-maximum) for the data showing a non-normal distribution. Nominal variables were given as the number of cases $(\mathrm{N})$ and percentages (\%). While the groups were compared with the t-test or the Mann-Whitney $U$ test, nominal variables were compared with the chi-square test or the Fisher's exact test. The significance level was taken as $p<0.05$.

\section{Results}

A total of 100 RA patients (78 females and 22 males) participated in the study, and the mean age of the participants was found to be 69.2. While the cut-off levels of FFMls were found to be $19.45 \mathrm{~kg} / \mathrm{m}^{2}$ for males and $17.85 \mathrm{~kg} / \mathrm{m}^{2}$ for females, the cut-off levels of MMls were found to be $18.47 \mathrm{~kg} / \mathrm{m}^{2}$ for males and $17.64 \mathrm{~kg} / \mathrm{m}^{2}$ for females. Therefore, the patients with values 2 standard deviation below the calculated cut-off levels were considered as sarcopenic, and all RA patients were divided into two groups. Accordingly, it was found that 35 patients had sarcopenia, which indicated that the prevalence rate was $35 \%$ among the patients.

The sarcopenic group was older than the non-sarcopenic one. Female/male ratio, smoking, alcohol use, disease duration, DAS-28 scores, and the numbers of patients with deformities were similar between the two groups. Uses of cDMARD, glucocorticoids, non-steroidal anti-iflammatory drugs, and statin did not show a significant difference between the groups. However, there were eight non-sarcopenic patients using bDMARD, while there was no bDMARD user in the sarcopenic group (Table 1). 
Considering anthropometric measurements, calf circumference was found to be shorter in the sarcopenic group, but the middle upper arm circumference was similar between the groups. Gait speed was slower, and handgrip strength was poorer in the sarcopenic group. While Body Mass index (BMI), FFMI, and MMI were significantly lower, the fat percentage was significantly higher in the sarcopenic group (Table 2).

Table 1. The demographics comorbidities and drug history of patients

\begin{tabular}{|c|c|c|c|}
\hline & $\begin{array}{l}\text { Sarcopenic } \\
(n=35)\end{array}$ & $\begin{array}{l}\text { Non- } \\
\text { sarcopenik } \\
(n=65)\end{array}$ & Significance \\
\hline Age $(M \pm S D)$ & $71.8 \pm 7.16$ & $67.94 \pm 5.67$ & $p=0.006$ \\
\hline Female gender, $\mathrm{n}$ & $28(80 \%)$ & $50(76.9 \%)$ & $p=0.466$ \\
\hline $\begin{array}{l}\text { RA median duration, } \\
\text { years }\end{array}$ & 6 & 4 & $p=0.613$ \\
\hline $\begin{array}{l}\text { Patients with } \\
\text { deformity, } n\end{array}$ & $6(17.1 \%)$ & $11(16.9 \%)$ & $p=0.592$ \\
\hline Diabetes & $10(28.1 \%)$ & $15(23.1 \%)$ & $p=0.355$ \\
\hline Hypertension & $17(48.6 \%)$ & $40(61.5 \%)$ & $p=0.15$ \\
\hline Cigarette smoking & $7(20 \%)$ & $16(24.6 \%)$ & $p=0.397$ \\
\hline Alcohol consumption & $2(5.7 \%)$ & $5(7.7 \%)$ & $p=0.712$ \\
\hline DAS-28 score & $2.65 \pm 1.2$ & $2.42 \pm 0.96$ & $p=0.284$ \\
\hline Glucocorticoid use & $30(75.7 \%)$ & $52(80 \%)$ & $p=0.337$ \\
\hline NSAID use & $19(54.3 \%)$ & $41(63.1 \%)$ & $p=0.266$ \\
\hline cDMARD use & 31 (88.6\%) & $61(93.8 \%)$ & $p=0.287$ \\
\hline bDMARD use & 0 & $8(12.3 \%)$ & $p=0.027$ \\
\hline Statin use & $4(11.1 \%)$ & $7(10.7 \%)$ & $p=0.92$ \\
\hline \multicolumn{4}{|c|}{$\begin{array}{l}\text { CDMARD: Conventional disease modified anti-rheumatic drugs, bDMARD: Biological } \\
\text { disease modified anti-rheumatic drugs, SD: Standard deviation, DAS-28: Disease } \\
\text { Activity score-28, RA: Rheumatoid arthritis, NSAID: Non-steroidal anti-iflammatory } \\
\text { drugs, M: Mean }\end{array}$} \\
\hline
\end{tabular}

Table 2. Anthropometric measurements and the results of bioimpedence anlayzes

\begin{tabular}{|l|l|l|l|}
\hline \multicolumn{2}{|l}{ Measures } & Sarcopenic & Non- \\
sarcopenic
\end{tabular}

The number of patients having depression and urinary incontinence was found to be similar between the groups. The dependence on ADL and IADL were significantly higher in the sarcopenic group. Frailty and malnutrition were found to be significantly more frequent in the sarcopenic group (Table 3).

In laboratory analyses, hemoglobin, estimated glomerular filtration rate, $25-\mathrm{OH}$ vitamin D levels were found to be similar by two-group comparisons. Both groups had similar RF and anti-CCP positive cases. The acute phase reactant (ESR and CRP) levels were significantly higher in the sarcopenic group (Table 4).

\section{Discussion}

The results of the present study showed that nearly one-third of RA patients had sarcopenia, and bDMARD use was less common in the sarcopenic group. The patients with sarcopenia also had higher acute phase reactant levels and higher dependence in ADL. There were no significant relationships between sarcopenia and diabetes, hypertension, alcohol use, smoking, medication history, hemoglobin levels, renal function, and vitamin D levels.

Both RA and sarcopenia were more prevalent in female patients, but it is known that prevalence rates become closer by aging $(11,12)$. The findings revealed that there was no association between sarcopenia and diabetes and hypertension, although

Table 3. The comparison of groups with comprehensive geriatric assessment

\begin{tabular}{|c|c|c|c|}
\hline & Sarcopenic & $\begin{array}{l}\text { Non- } \\
\text { sarcopenic }\end{array}$ & Significance \\
\hline Urinary incontinence & $12(34.3 \%)$ & $14(21.4 \%)$ & $p=0.126$ \\
\hline Dependence on ADL & $10(28.6 \%)$ & 0 & $p<0.001$ \\
\hline Dependence on IADL & $20(57.1 \%)$ & $23(35.4 \%)$ & $p=0.03$ \\
\hline Depression & $17(48.6 \%)$ & $31(47.7 \%)$ & $p=0.55$ \\
\hline Frailty & $19(54.3 \%)$ & $22(33.8 \%)$ & $p=0.039$ \\
\hline Malnutrition & $11(31.4 \%)$ & $7(10.8 \%)$ & $p=0.012$ \\
\hline
\end{tabular}

Table 4. Two-group comparisons of laboratory values

\begin{tabular}{|c|c|c|c|}
\hline & Sarcopenic & $\begin{array}{l}\text { Non- } \\
\text { sarcopenic }\end{array}$ & Significance \\
\hline Hemoglobin level, g/dL & $12.28 \pm 1.27$ & $12.54 \pm 1.55$ & $p=0.820$ \\
\hline $\mathrm{eGFR}, \mathrm{mL} / \mathrm{min} / 1.73 \mathrm{~m}^{2}$ & $76.06 \pm 22.27$ & $77.98 \pm 21.8$ & $p=0.677$ \\
\hline $\begin{array}{l}\text { 25-OH vitamin D, } \\
\mathrm{nmol} / \mathrm{L}\end{array}$ & $20.1 \pm 2$ & $21 \pm 1.8$ & $p=0.480$ \\
\hline RF seropositivity, $n$ & $17(48.6 \%)$ & $37(56.9 \%)$ & $p=0.278$ \\
\hline Anti-CCP positivity, n & $17(48.6 \%)$ & $33(50.6 \%)$ & $p=0.834$ \\
\hline $\mathrm{ESR}, \mathrm{mm} / \mathrm{h}$ & $26(3-93)$ & $21(5-104)$ & $p=0.033$ \\
\hline CRP, mg/L & $10.9(1-78)$ & $4(1-28)$ & $p=0.015$ \\
\hline
\end{tabular}


the relevant literature showed controversial results (13-16). The relationship between alcohol use and sarcopenia was also not clear $(15,17)$.

In a study conducted by Giles et al. (18), smoking, disease activity, seropositivity with RF, and uses of cDMARD, bDMARD, and glucocorticoid among the participants showed a similarity with the relevant data in our study. However, they found the sarcopenia prevalence as $25.9 \%$.

Scott et al. (19) showed that statins might decrease muscle performance and increase falls. In our study, there was no significant difference in the use of statin, which could have toxic effects on muscle, among the participants.

Although the findings regarding biological DMARDs were not clear, a study showed that etanercept might cause weight gain in the early stages of RA before the involvement of cachexia (20).

Yamada et al. (21) concluded that RA patients using glucocorticoids at a dose above $3.25 \mathrm{mg}$ through a year had a higher risk for developing sarcopenia. Such a finding was also contradictory to our findings of glucocorticoid use.

Another study conducted with female RA patients aged 35-50 years showed that sarcopenia had no significant relationship with disease activity and medication. Moreover, CRP levels were found to be higher in patients with sarcopenia, which is similar to our study (22).

A study investigated sarcopenia-related factors in Japanese patients with RA. The prevalence was found to be $29.6 \%$. Furthermore, age, BMI, CRP levels, and hip bone mineral density were significant sarcopenia-related factors, which supports our findings. Nevertheless, the study found bDMARD had no relationship with sarcopenia, and MNA was not significant in the multivariate analysis (23). These findings are different from ours.

Barone et al. (24) conducted a study to investigate sarcopenia in different rheumatic diseases, such as RA, psoriatic arthritis, and ankylosing spondylitis. The patients were aged between 40 and 75 years. Although the study employed a different design, it also included presarcopenia. The prevalence of sarcopenia was found to be $20 \%$. They concluded that only age and presence of disability were associated with an increased risk of sarcopenia.

Torii et al. (25) investigated sarcopenia-associated factors in RA patients. The prevalence was found to be $37.1 \%$. Age, RA duration, MNA score, and bDMARD use were significant factors affecting sarcopenia. The findings were similar to ours, except for the RA duration.

Ngeuleu et al. (26) found that sarcopenic and non-sarcopenic patients with RA had different ages and CRP levels, but similar disease duration and activity, RF, and anti-CCP seropositivity.
These findings are similar to ours. Additionally, they showed that excessive fat and bone erosion, increased cardiometabolic risk, and BMI were related to sarcopenia.

It has been approved by various studies that malnutrition is a major factor in the etiology of sarcopenia (27). In our findings, malnutrition was found to be more frequent in RA patients with sarcopenia. Besides, there are controversial results in some studies conducted with RA patients (25).

Urinary incontinence was more frequent in the sarcopenic group while it was not statistically significant. A study showed that hospitalized sarcopenic patients with coronary heart disease had higher urinary incontinence rates (28). Nevertheless, it could not be found a study assessing urinary incontinence in RA patients with sarcopenia.

Calf circumference was found to be lower in the sarcopenic group, while middle upper arm circumference was similar in the two groups. Some studies showed that calf circumference was an essential predictor of sarcopenia prognosis and diagnostic tools. Sarcopenia may decrease upper arm circumference (29). The middle upper arm circumference was not different between sarcopenic the groups in our study, as contradictory to literature, but it may be related to the sample characteristics.

Finally, the study has several limitations. First off, the sample size was rather small. Secondly, more certain diagnostic tools, such as quantitative computerized tomography, magnetic resonance, etc, were not used. Secondly, the deformity and activity of RA may lead to mobility problems and some tests such as gait speed or handgrip strength may prevent the correct assessment. Then, this was a cross-sectional study, and more comprehensive followup studies are considered to explain the associated factors in detail. On the other hand, this is the first study investigating the relationship between sarcopenia and certain factors such as depression, alcohol use, urinary incontinence, etc.

\section{Conclusion}

Overall, sarcopenia is a significant clinical problem that affects the geriatric population. The patients with autoimmune disorders, such as RA, suffer from disabilities, and dependence in ADL. Sarcopenia, nutritional status, and frailty should always be kept in mind for RA patients. Moreover, RA patients should be evaluated for sarcopenia through anthropometric measurements, analysis of body components, and laboratory tests. Finally, the increase in acute phase reactants should be assessed in terms of sarcopenia.

\section{Ethics}

Ethics Committee Approval: Ankara University Institutional Review Board approved the study (number: 10-427-14, date: 09/06/2014). 
Informed Consent: The signed informed consent form was obtained from all participants.

Peer-review: Internally peer-reviewed.

\section{Authorship Contributions}

Surgical and Medical Practices: I.K., E.Ç., Ö.K.C., Concept: S.A., E.Ç., Ö.K.C., Design: S.A., M.V., T.A., Data Collection or Processing: I.K., E.Ç., Ö.K.C., Analysis or Interpretation: I.K., M.V., T.A., Literature Search: I.K., M.V., T.A., Writing: I.K., S.A., T.A.

Conflict of Interest: No conflict of interest was declared by the authors.

Financial Disclosure: The authors declared that this study received no financial support.

\section{References}

1. Cruz-Jentoft AJ, Baeyens JP, Bauer JM, Boirie $Y$, Cederholm T, Landi $F$, Martin FC, Michel JP, Rolland Y, Schneider SM, Topinková E, Vandewoude M, Zamboni M; European Working Group on Sarcopenia in Older People. Sarcopenia: European consensus on definition and diagnosis: Report of the European Working Group on Sarcopenia in Older People. Age Ageing 2010;39:412-423.

2. Cruz-Jentoft AJ, Bahat $G$, Bauer J, Boirie $Y$, Bruyère 0 , Cederholm T, Cooper C, Landi F, Rolland Y, Sayer AA, Schneider SM, Sieber CC, Topinkova E, Vandewoude M, Visser M, Zamboni M; Writing Group for the European Working Group on Sarcopenia in Older People 2 (EWGSOP2), and the Extended Group for EWGSOP2. Sarcopenia: Revised European consensus on definition and diagnosis. Age Ageing 2019;48:16-31.

3. Fielding RA, Vellas B, Evans WJ, Bhasin $S$, Morley JE, Newman AB, Abellan van Kan G, Andrieu S, Bauer J, Breuille D, Cederholm T, Chandler J, De Meynard C, Donini L, Harris T, Kannt A, Keime Guibert F, Onder G, Papanicolaou D, Rolland Y, Rooks D, Sieber C, Souhami E, Verlaan S, Zamboni M. Sarcopenia: An Undiagnosed Condition in Older Adults. Current Consensus Definition: Prevalence, Etiology, and Consequences. International Working Group on Sarcopenia. J Am Med Dir Assoc 2011;12:249-256.

4. Hanaoka BY, Ithurburn MP, Rigsbee CA, Bridges SL, Moellering DR, Gower B, Bamman M. Chronic Inflammation in Rheumatoid Arthritis and Mediators of Skeletal Muscle Pathology and Physical Impairment: A Review. Arthritis Care Res 2019;71:173-177.

5. Elkan AC, Engvall IL, Cederholm T, Hafström I. Rheumatoid cachexia, central obesity and malnutrition in patients with low-active rheumatoid arthritis: Feasibility of anthropometry, Mini Nutritional Assessment and body composition techniques. Eur J Nutr 2009;48:315-322.

6. da Costa JP, Vitorino R, Silva GM, Vogel C, Duarte AC, Rocha-Santos T. A synopsis on aging-Theories, mechanisms and future prospects. Ageing Res Rev 2016;29:90-112.

7. Dello SAWG, Lodewick TM, Van Dam RM, Reisinger KW, Van Den Broek MAJ, Von Meyenfeldt MF, Bemelmans MH, Olde Damink SW, Dejong CH. Sarcopenia negatively affects preoperative total functional liver volume in patients undergoing liver resection. HPB 2013;15:165-169.

8. Shankar P. Frailty, muscle atrophy, and sarcopenia. J Mahatma Gandhi Inst Med Sci 2013;18:91.

9. Mühlberg W, Sieber C. Sarcopenia and frailty in geriatric patients: Implications for training and prevention. Zeitschrift fur Gerontologie und Geriatrie 2004;37:2-8.

10. Ethgen 0 , Beaudart C, Buckinx $F$, Bruyère 0 , Reginster JY. The Future Prevalence of Sarcopenia in Europe: A Claim for Public Health Action. Calcif Tissue Int 2017;100:229-234.
11. Akkoc N. Türkiye'de Romatizmal Hastalıkların Epidemiyolojisi ve Diğer Ülkelerle Karşılaştırılması. RAED Derg 2010;2:1-8.

12. Demir Göçmen D, Gedik E, Bulunmaz I, Kafkasli Ai, Mert M, Kandemir A, Bingol U, Altan Inceoglu L, Atik T. Klinik Araştırma Romatoid Artrit Tanısıyla İzlenen Hastalarımızın Klinik, Laboratuvar ve Demografik Özellikleri: Beş Yıl İzlem Süreli Gözlemsel Çalışma. Fırat Tıp Derg 2011;16:55-59.

13. Park SW, Goodpaster BH, Strotmeyer ES, De Rekeneire N, Harris TB, Schwartz A $V$, Tylavsky FA, Newman AB. Decreased muscle strength and quality in older adults with type 2 diabetes: The health, aging, and body composition study. Diabetes 2006;55:1813-1818.

14. Andersen $H$, Nielsen $S$, Mogensen $C E$, Jakobsen J. Muscle strength in type 2 diabetes. Diabetes 2004;53:1543-1548.

15. Castillo EM, Goodman-Gruen D, Kritz-Silverstein D, Morton DJ, Wingard DL, Barrett-Connor E. Sarcopenia in elderly men and women: The Rancho Bernardo study. Am J Prev Med 2003;25:226-231.

16. Sanada $K$, Miyachi $M$, Tanimoto $M$, Yamamoto $K$, Murakami $H$, Okumura S, Gando Y, Suzuki K, Tabata I, Higuchi M. A cross-sectional study of sarcopenia in Japanese men and women: Reference values and association with cardiovascular risk factors. Eur J Appl Physiol 2010;110:57-65.

17. Lau EMC, Lynn HSH, Woo JW, Kwok TCY, Melton L. Prevalence of and risk factors for sarcopenia in elderly Chinese men and women. J Gerontol A Biol Sci Med Sci 2005;60:213-216.

18. Giles JT, Ling SM, Ferrucci L, Bartlett SJ, Andersen RE, Towns M, Muller D, Fontaine KR, Bathon JM. Abnormal body composition phenotypes in older rheumatoid arthritis patients: Association with disease characteristics and pharmacotherapies. Arthritis Care Res 2008;59:807-815.

19. Scott D, Blizzard L, Fell J, Jones G. Statin therapy, muscle function and falls risk in community-dwelling older adults. OJM 2009;102:625-633.

20. Marcora SM, Chester KR, Mittal G, Lemmey AB, Maddison PJ. Randomized phase 2 trial of anti-tumor necrosis factor therapy for cachexia in patients with early rheumatoid arthritis. Am J Clin Nutr 2006;84:1463-1472.

21. Yamada Y, Tada M, Mandai K, Hidaka N, Inui K, Nakamura H. Glucocorticoid use is an independent risk factor for developing sarcopenia in patients with rheumatoid arthritis: from the CHIKARA study. Clin Rheumatol 2020;39:1757-1764.

22. Ceyhan Dogan S, Hizmetli S, Hayta E, Kaptanoglu E, Erselcan T, Guler E. Sarcopenia in women with rheumatoid arthritis. Eur J Rheumatol 2015;2:57-61.

23. Mochizuki T, Yano K, Ikari K, Okazaki K. Sarcopenia-associated factors in Japanese patients with rheumatoid arthritis: A cross-sectional study. Geriatr Gerontol Int 2019;19:907-912.

24. Barone M, Viggiani M, Anelli M, Fanizzi R, Lorusso O, Lopalco G, Cantarini L, Di Leo A, Lapadula G, lannone F. Sarcopenia in Patients with Rheumatic Diseases: Prevalence and Associated Risk Factors. J Clin Med 2018;7:504.

25. Torii $M$, Hashimoto $M$, Hanai $A$, Fujii $T$, Furu $M$, Ito $H$, Uozumi $R$, Hamaguchi M, Terao C, Yamamoto W, Uda M, Nin K, Morita S, Arai H, Mimori T. Prevalence and factors associated with sarcopenia in patients with rheumatoid arthritis. Mod Rheumatol 2019;29:589-595.

26. Ngeuleu A, Allali F, Medrare L, Madhi A, Rkain H, Hajjaj-Hassouni N. Sarcopenia in rheumatoid arthritis: prevalence, influence of disease activity and associated factors. Rheumatol Int 2017;37:1015-1020.

27. Cruz-Jentoft AJ, Landi F, Topinková E, Michel JP. Understanding sarcopenia as a geriatric syndrome. Current Opinion in Clinical Nutrition and Metabolic Care 2010;13:1-7.

28. Zhang N, Zhu W, Liu X, Chen W, Zhu M, Sun X, Wu W. Related factors of sarcopenia in hospitalized elderly patients with coronary heart disease. Zhonghua Xin Xue Guan Bing Za Zhi 2019 24;47:979-984.

29. Maeda K, Koga T, Nasu T, Takaki M, Akagi J. Predictive Accuracy of Calf Circumference Measurements to Detect Decreased Skeletal Muscle Mass and European Society for Clinical Nutrition and Metabolism-Defined Malnutrition in Hospitalized Older Patients. Ann Nutr Metab 2017;71:1015. 